www.jmscr.igmpublication.org

Index Copernicus Value: 79.54

ISSN (e)-2347-176x ISSN (p) 2455-0450

crossrefDOI: https://dx.doi.org/10.18535/jmscr/v7i3.46

\title{
A Study on Management of hangman`s Fracture
}

Authors

\section{Dr SIM Khairun Nabi Khan', Dr Moshiur Rahman², Dr Robert Ahmed Khan ${ }^{3}$, Dr Sk. Farhad Munir ${ }^{4}$, Dr Sujan Sharif ${ }^{5}$ \\ ${ }^{1}$ Assistant Professor, Neurosurgery Department, BSMMU, Bangladesh}

${ }^{2}$ Assistant Professor, Neurosurgery Department, Holy Family Red Crescent Medical College, Bangladesh

${ }^{3,4}$ Medical Officer, Neurosurgery Department, BSMMU

${ }^{5}$ Medical Officer (Resident), BSMMU

\begin{abstract}
Introduction: Traumatic spondylolisthesis of $C 2$ (Axis) which is also known as hangman fracture was initially noted in 1965 by Schneider et al. There are two kinds of it, i.e. (i) one of a hyperextensivedistractive mechanism with the very severe neurological lesion leading to the classical injury due to hanging and (ii) one of a hyperextensive-compressive mechanism without neurological lesion of current traffic injuries or with slight neurological symptoms. The latter more often occurring type of injury encompasses a relatively wide range. The optimal therapy for traumatic fractures of the neural arch of the axis is still controversial. Indications for surgery depend on the type of hangman's fracture and/or additional injuries of the intervertebral disc or ligaments. Here we shall share our experience of surgical management of hangman's fracture with review of literature.

Method: 29 patients with hangman's fracture were treated between 2004 and 2015. All patients presented with neck pain and 7 with neurological deficit. 3 patients with stable fracture were treated by rigid collar. Of the 17 surgically treated patients 16 were managed with screws, placed on the C2 pedicles. Of them 7 required additional fixation with rod \& screw on the lateral masses of $C 3$ and another with $C 4$ pedicle screw as he had associated C3 body fracture. 1 patient underwent anterior discectomy and fusion with internal fixation.

Results: All the patients had good post surgical outcome with satisfactory fusion of the fractures.

Conclusions: Surgery provides plausible results. Compared to conservative treatment, it can offer significant benefits: 1) immediate, better and stable reposition; 2) high fusion rate; 3) shortening of the treatment period with better quality of life. Though technically difficult, transpedicular screw fixation is the best option as it preserves the motion more than other techniques.

Keywords: Traumatic spondylolisthesis, hyperextensive, hangman's fracture.
\end{abstract}

\section{Introduction}

Hangman's fractures have been used to describe traumatic spondylolisthesis of C2 since it was initially noted in 1965 by Schneider et $\mathrm{al}^{[1]}$. It is defined as laminate fractures, articulate facets, pedicles or parses of the vertebra axis. Fractures in Hangman are often caused by accidents in the fall, diving or motor vehicle. The typical fractures of the hangman are those with the back side of the vertebral body on one or both sides, as opposed to 
the neural $\operatorname{arch}^{[2]}$. In contrast to atypical hangman fractures, asymmetric fractures were more recently defined as a pars interarticularis fracture on one side of the neural arch plus another fractured component, either the rear cortex of the C2 body or the rear neural arch elements on the other ${ }^{[3]}$.

Hangman's fractures account for 20 to 22 percent of all axis fractures and are one of the most common types of high cervical spinal injury [46].This injury occurs most often during road traffic accidents (RTAs) and falls due to cervical hyperextension and axial loading ${ }^{[7,8,5,9]}$.

Management guidelines in the literature are based on level III evidence. A recent review concluded that external immobilization is recommended as initial management of traumatic spondylolisthesis, with surgical stabilization and fusion reserved for cases of severe angulation of $\mathrm{C} 2$ to $\mathrm{C} 3$, disruption of C2-C3 disk space and/or failure to achieve or maintain alignment of fracture with external immobilization $^{[10]}$.

Table 1: Classification of Hangman's Fracture

\begin{tabular}{|l|c|c|}
\hline \multicolumn{2}{|c|}{ Classification } & \multicolumn{2}{c|}{ Definition } & Mechanism \\
\hline Type I & $\begin{array}{c}\text { Isolated hairline fracture of ring of } \\
\text { axis }\end{array}$ & Axial loading and hyperextension \\
\hline Type II & $\begin{array}{c}\text { Displacement of anterior fragment } \\
\text { and abnormal disk below axis }\end{array}$ & $\begin{array}{c}\text { Further hyperextension and rebound } \\
\text { flexion }\end{array}$ \\
\hline Type III & $\begin{array}{c}\text { Displacement of anterior fragment } \\
\text { andlocked facet at C2-C3 }\end{array}$ & Flexion and rebound extension \\
\hline \multicolumn{2}{|c|}{ Levine and Edwards } \\
\hline Type I & Non displaced fracture (<3 mm) & Hyperextension and axial loading \\
\hline Type II & $\begin{array}{c}\text { Significant angulation (>11 degrees) } \\
\text { and translation (>3 mm) }\end{array}$ & $\begin{array}{c}\text { Hyperextension, axial loading and } \\
\text { rebound flexion }\end{array}$ \\
\hline Type IIa & $\begin{array}{c}\text { Very severe angulation without } \\
\text { translation }\end{array}$ & Flexion-distraction \\
\hline Type III & $\begin{array}{c}\text { Severe angulation and displacement } \\
\text { with facet dislocation }\end{array}$ & Flexion-compression \\
\hline
\end{tabular}

(Source: "Management of Typical and Atypical Hangman's Fractures", Rafid Al-Mahfoudh et al. Global Spine J 2016;6:248256)

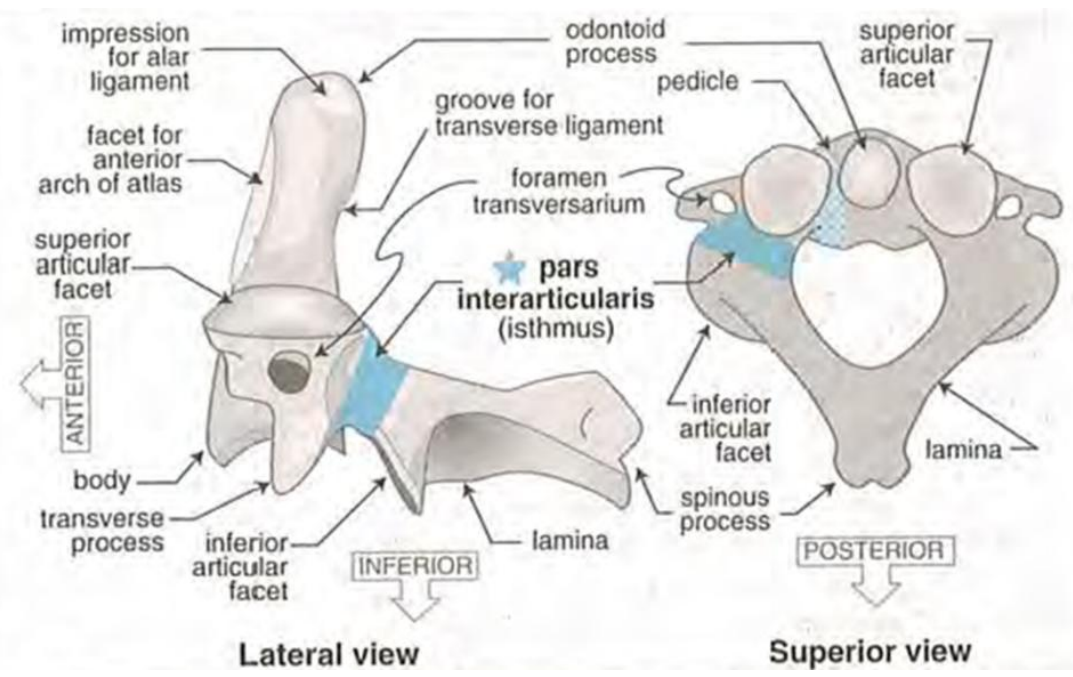

Figure-1: Anatomy of axis

Above illustration shows the lateral and superior views of axis. 

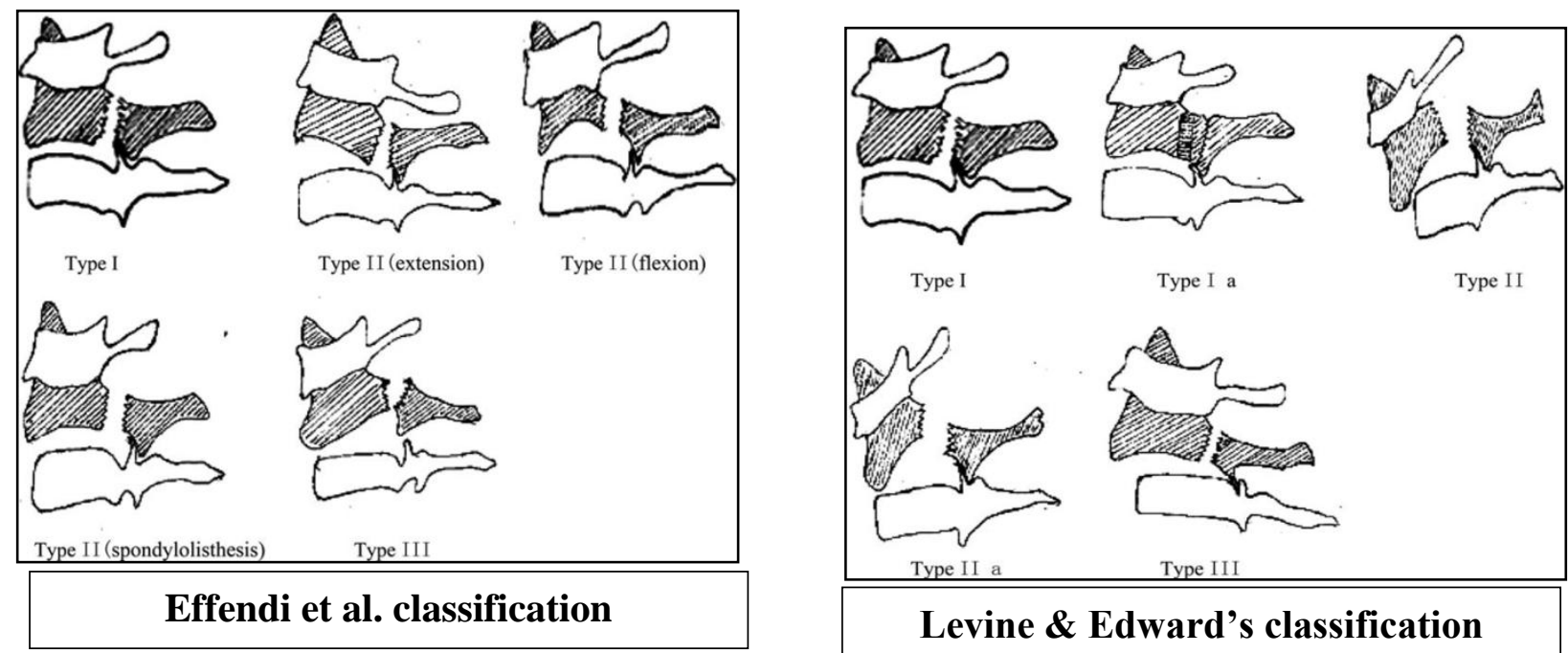

\section{Levine \& Edward's classification}

Figure-2: Type of Hangman's Fracture

On both classification Type I is stable and Type II \& Type III are unstable fractures.

\section{Methods}

The study was carried out at the Department of Neurosurgery at the Bangabandhu Sheik Mujib Medical University (BSMMU) in Dhaka, between 2004 to 2015. In order to identify patients, a prospective clinical database of 29 patient records coded as "axis fractures" was used.All radiological and $\mathrm{X}$ - ray records have been reviewed. All patients with hangman fractures had inclusion criteria; no exclusion criteria existed. The study has been evaluated and endorsed by an internal review committee.

The clinical notes were reviewed retrospectively for information on the injury mechanism, associated injury, comorbidity, presentation, management and follow- up with regard to clinical and radiological results. The clinical results included complications in the management, pain scores and reported neck rigidity. The radiological results have been independently examined by a neuroradiologist; the osseous union has been evaluated on computed tomography $(\mathrm{CT})$ or plain radiographs.

\section{Inclusion Criteria}

$>19$ patients had MVA, 8 had a fall, 1 had fall of heavy weight on head and 1 had veil tangled around the neck.

\section{Clinical presentation \& investigation}

$>$ The entire patient had neck pain. 14 patient presented with neurological deficit 3 had stable fracture.

$>$ All the patients were evaluated with dynamic $x$-ray of cervical spine under supervision. Most of the patients were further assessed by MRI and CT scan.

\section{Types of management}

$>3$ patients with stable fracture were treated with rigid collar. Other 22 patients were treated surgically.

Of the surgically treated patients 14 were submitted to arthrodesis of the fractures with two screws, placed on the C2 pedicles, which allowed a better approximation of the fractures with the alignment of $\mathrm{C} 2-\mathrm{C} 3$. Of them 7 ss required additional fixation with rod \& screw on the lateral masses of $\mathrm{C} 3.1$ patient underwent anterior discectomy and fusion with internal fixation. 


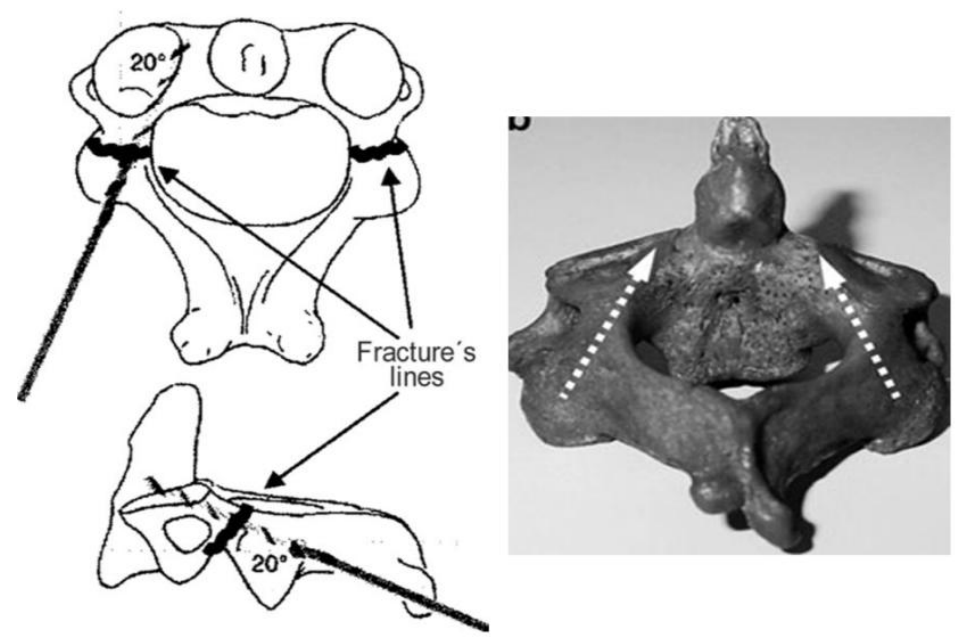

Figure-3: Direction of transpedicular screw placement

Case-1: 32 years female injured by Motor Vehicle Accident (MVA)
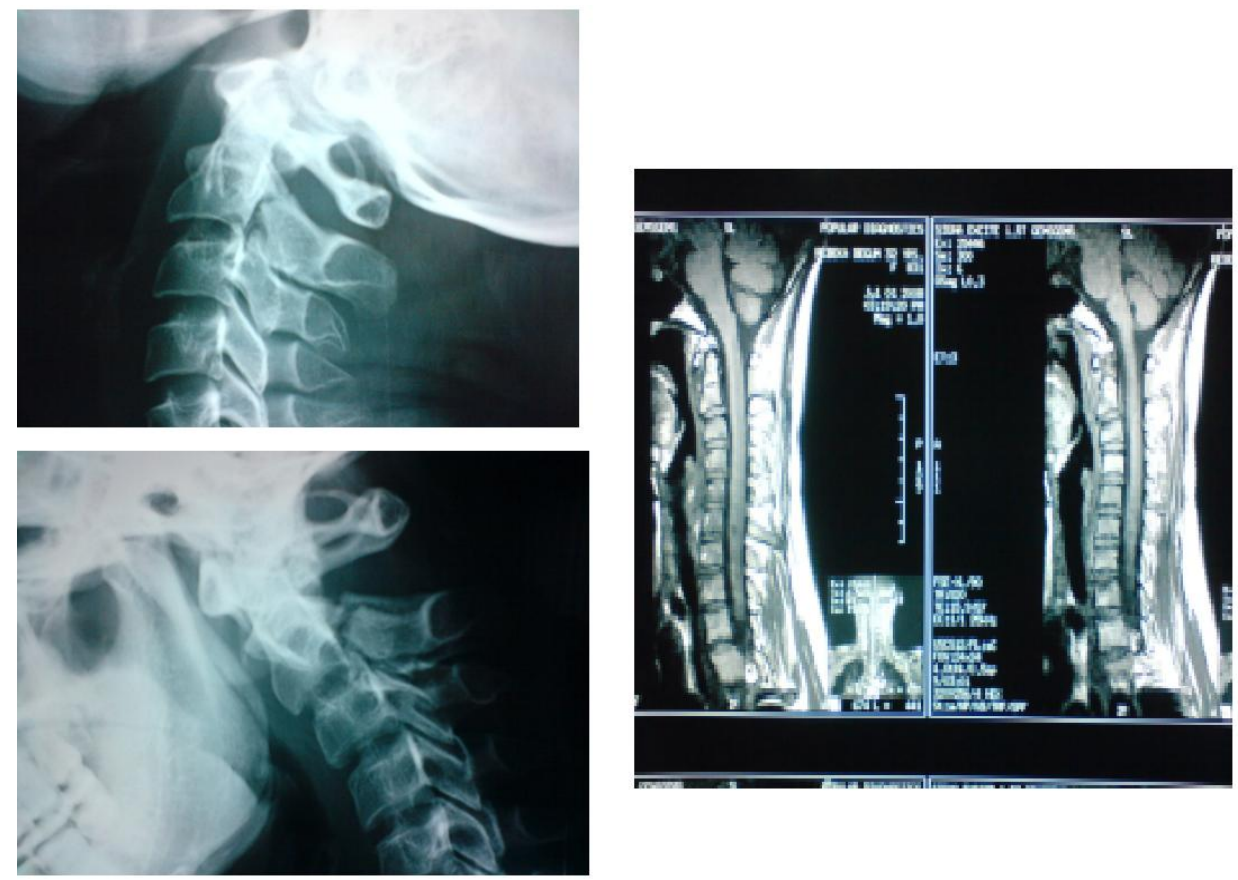

Case-2: 25 y Female, H/O fall associated KFS
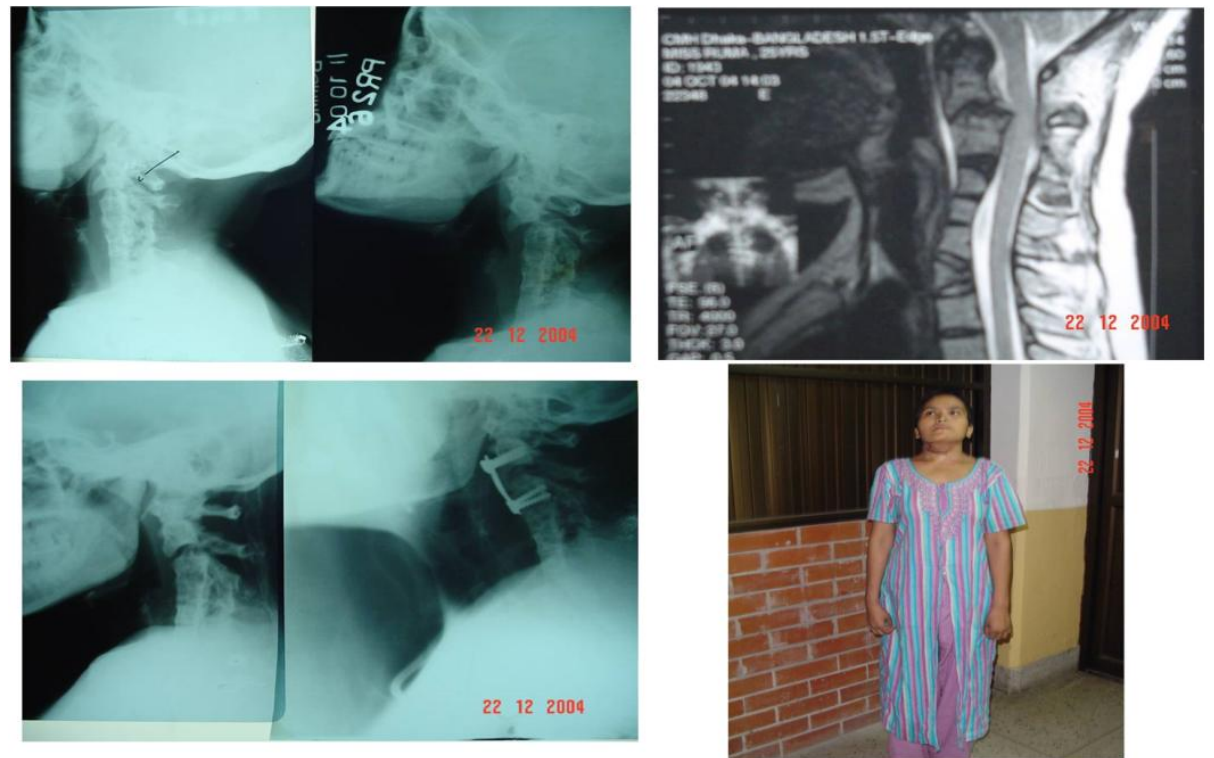


\section{JMSCR Vol||07||Issue||03||Page 258-263||March

Case-3: 26 y Male, MVA
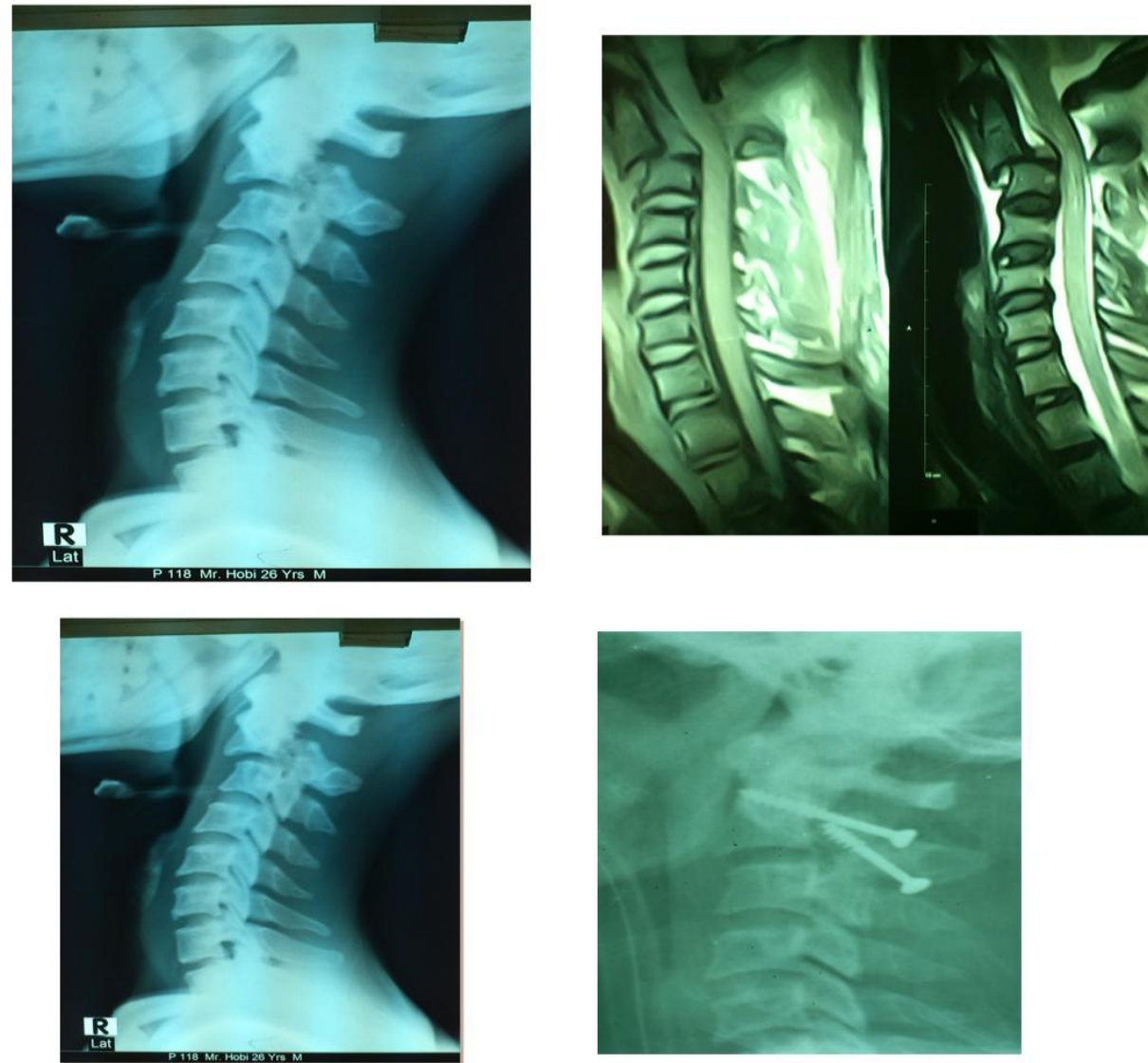

Pre \& Post-operative x-ray imaging

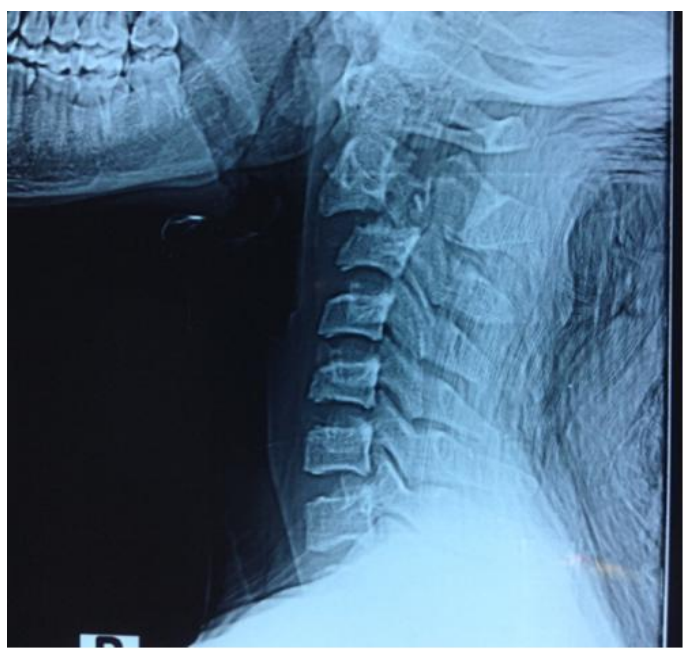

Figure-4: Partial correction after traction

\section{Result}

$>$ Most hangman's fractures could be managed successfully with traction and external immobilization, especially in Effendi Type I,Type II and LevineEdwards Type IIfractures.

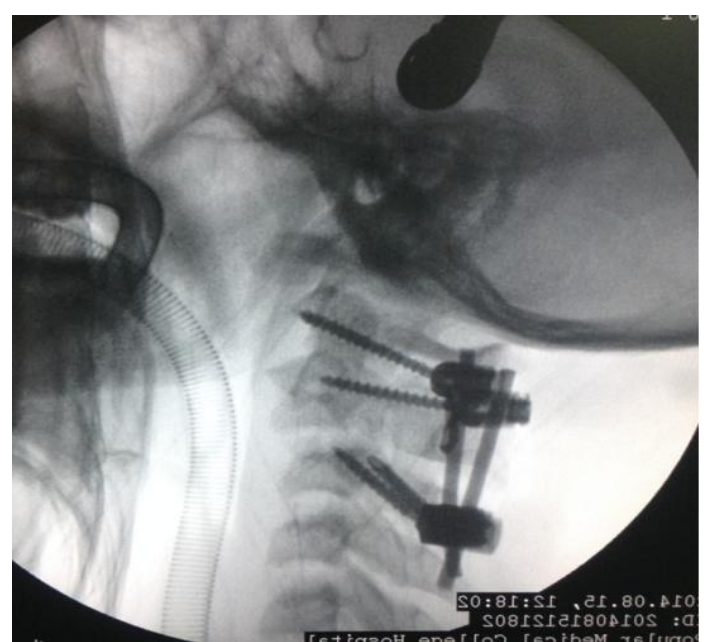

Figure-5: Full correction after surgery

Levine- Edwards fractures of type II a and III must be treated with rigid immobilisation.

$>$ All the patients had good post surgical outcome with disappearance of symptoms and improvement of neurological state. 


\section{Discussion}

This retrospective analysis was intended to analyze the patterns of the fractures of hangman and to audit our treatment methods. We have tried to determine whether treatment failures with cervical collars are more likely than with halo immobilization.

\section{Conclusion}

$>$ Surgery provides plausible results.

$>$ Compared to conservative treatment, it can offer significant benefits.

- Immediate, better and stable reposition.

- High fusion rate.

- Shortening of treatment period with better quality of life.

Though technically difficult transpedicular screw fixation is the best option as it is physiologically and biomechanically most sound.

\section{Reference}

1. Schneider RC, Livingston KE, Cave AJ, Hamilton G (1965) "Hangman's fracture" of the cervical spine. J Neurosurg 22:141154.

2. Burke JT, Harris JH Jr. Acute injuries of the axis vertebra. Skeletal Radiol 1989;18(5):335-346

3. Samaha C, Lazennec JY, Laporte C, Saillant G. Hangman's fracture: the relationship between asymmetry and instability. J Bone Joint Surg $\mathrm{Br}$ 2000;82(7):1046-1052

4. Greene KA, Dickman CA, Marciano FF, Drabier JB, Hadley MN, Sonntag VK. Acute axis fractures. Analysis of management and outcome in 340 consecutive cases. Spine (Phila Pa 1976) 1997; 22(16):1843-1852
5. Ferro FP, Borgo GD, Letaif OB, Cristante AF, Marcon RM, Lutaka AS. Traumatic spondylolisthesis of the axis: epidemiology, management and outcome. ActaOrtop Bras 2012;20(2):84-87

6. Hadley MN, Dickman CA, Browner CM, Sonntag VK. Acute axis fractures: a review of 229 cases. J Neurosurg 1989;71(5 Pt 1): 642-647

7. Schneider RC, Livingston KE, Cave AJ, Hamilton G. "Hangman's fracture" of the cervical spine. J Neurosurg 1965;22(2): $141-154$

8. Coric D, Wilson JA, Kelly DL Jr. Treatment of traumatic spondylolisthesis of the axis with nonrigid immobilization: a review of 64 cases. J Neurosurg 1996;85(4):550-554

9. White AA III, Panjabi MM. The clinical biomechanics of the occipitoatlantoaxial complex. OrthopClin North Am 1978;9(4): $867-878$

10. Ryken TC, Hadley MN, Aarabi B, et al. Management of isolated fractures of the axis in adults. Neurosurgery 2013;72 (Suppl 2):132-150. 